\title{
Ambiguity and Nominal Group Multiple Post modification in the Written English of Some Selected Nigerian Polytechnics
}

Bidemi Okanlawon (PhD) and Samson Oluga

\section{Abstract}

Semantic clarity and completeness of idea are two fundamental characteristics of virtually all forms of continuous writing especially essays, letters and reports. However, multiple post-modification of nominal groups often used to achieve clarity and brevity sometimes subjects ideas to ambiguity thereby making them to be susceptible to double or multiple semantic interpretations. This paper presents the outcome of a linguistic study of the continuous writing essays, letters and reports in the scripts of eighty [80] students of The Federal Polytechnic, Ede, Nigeria offering English courses as compulsory minors. The paper identifies multiple post modification in the usage of the English nominal groups and their tendency to lead to ambiguity. A syntacticsemantic analysis of the ambiguous expressions resulting from multiple post modification is presented detailing the sources of ambiguities that arise. Finally, possible disambiguation methods are suggested especially for English as a second language writers and readers.

Key words: Ambiguity and Nominal Group Multiple Postmodification

\section{Introduction}

This study sought to examine the continuous writing of Nigerian Polytechnic students, particularly the usage of syntactic organization in the English nominal group and its relationship to the conveyance of message, which is the essence of the communicative function of language. In English 
as a second language environment like Nigeria attention has to be focused not only on the form of utterance but also the ability of learners to fulfill communicative functions in English. Indeed, for Systemic Functional Linguistics language is seen as a 'system of meanings'. Bloor and Bloor (2004:2) assert that

When people use language, their language acts produce or, or more technically, construct meaning. From this point of view, grammar becomes a study of how meanings are built up through the choice of words and other grammatical resources such as singular or plural, negative or positive, and other linguistic forms such as tone and emphasis.

The paper's major aim is to examine multiple postmodification in the English nominal group as used by selected Nigerian Polytechnic students, and in order to achieve this aim, this study identified the instances of multiple postmodification in the nominal group in the data, examined the ambiguous expressions resulting from such usage and suggested solutions to remedy the problems.

The word modification, according to Cayne and Lechner (1992), refers to the process of limiting, expanding or qualifying the basic meaning of a word, phrase etc. using appropriate modifiers. Modification, therefore, usually adds to the meaning of modified items or sheds more light on the way they are to be understood. However, such modification can either be simple or complex modification and can be either 
Ambiguity and Nominal Group Multiple Post Modification...

premodification or postmodification. However, our focus in this paper is on postmodification.

What is postmodified is the Head or Thing which is an obligatory element of the English nominal group structure. Thing is usually realized by a noun, pronoun or a deverbal nominal item. Thing, according to Bloor \& Bloor (2004:12) may be "a material inanimate thing, an animal, a person a substance or even an abstract concept'.

Post modification in the English nominal group, according to Quirk (1985: 1239), comprises all items placed after the head, notably:

prepositional phrase: the car outside the station

non-finite clause: the car standing outside the station

relative clauses: the car that stood outside the station

complementation: a bigger car than that

Halliday (1994:66) also notes that "unlike the elements that precede the Thing, which are words..., what follows the Thing is either a phrase of a clause. With only rare exceptions, all Qualifiers are EMBEDDED". Appositive nominal groups e.g. "Jones, the goal keeper" and appositive clauses can also serve as post modifying items. An appositive clause links units with identical reference or grammatical affinity and the head of the nominal group must be a general abstract noun like fact, idea, proposition etc. as in the following example:

The fact that people reacted is obvious

Adjectives can also be used as post modifying elements. Quirk et al (1985: 1293 - 1294) posit that post posed adjectives can be divided into three main types depending on whether the post position is required by:

a. the head of the noun phrase e.g. 
I want to try something different (as opposed to a different approach)

b. the post modification or complementation of adjective e.g. a play popular in the 1890 s (as opposed to a popular play)

c. the particular noun - adjective combination e.g. the heir apparent (as opposed to the apparent reason, the rich heir)

We can have both simple post modification and multiple post modification. Simple post modification can be found in examples such as "president elect", "students on probation" etc. where the head has only one post modifier. With multiple post modification, a single head has more than one post modifying element e.g.

The lady in the car reading a newspaper

Where "in the car" is the first post modifier while the second post modifier is "reading a newspaper" which modifies the first post modifier and the preceding items. In multiple post modification, a modification may apply to more than one head e.g.

\section{The man and the lady in the car}

Where "in the car" can apply to either just 'the lady' or to both heads "the man" and "the lady".

Multiple post modification raises problems more especially for users of English as a second language. The careful ordering of items which is crucial for communication, even if it can be taken for granted in English as a mother tongue situation, can not be assumed in English as a second 
Ambiguity and Nominal Group Multiple Post Modification...

language situation. When items that require careful ordering are arranged haphazardly, we can have ambiguous or unacceptable structures. On this issue, Quirk et al (1972:899) assert that, "frequently, however, careful ordering of constituents in a noun phrase is essential to communicate all and only one's intention".

In this study, therefore, our focus is on ambiguity that results from multiple post modification in the continuous writing of selected Nigerian polytechnic students.

\section{Ambiguity}

Ambiguity is a linguistic concept that has attracted a number of definitions by lexicographers, semanticists, grammarians etc. Hirst (1982) contends that semantic description or interpretation refers to the process of mapping a syntactically analysed text of a natural language to a representation of meaning. He then defines ambiguity as a condition in which a formal item satisfies more than one semantic description or interpretation. Ruwet (1987) defines ambiguity as that having a single representation at a given level and at least two at one other level. An ambiguous expression according to Kent (1990) is an expression that can be taken or understood in more than one way and which can be avoided by changing the order of things. Hornby (2000) in his, lexicographical contribution to the meaning of the concept defines/ interpretes the noun 'ambiguity' and its adjectival form "ambiguous" as " the presence of more than one meaning" and "having more than one possible meaning" respectively. Oluga (2003 also defines ambiguity as the susceptibility of a lexical item or an expression to double or multiple semantic interpretations.

However, various types of ambiguity have been identified and different factors have been used in their identification or classification. Some contributors have, 
therefore, identified some types that others have not identified hence; the classification is not a water tight one. Some types are commonly identified by many contributors, and these are lexical ambiguity, syntactic ambiguity, phonological ambiguity and semantic ambiguity which are discussed below:

\section{Lexical Ambiguity}

Lexical ambiguity according to Trask (1993) occurs because of the complex meaning of a given word in a given utterance. This to Hirst (1982) is a situation where a given word is capable of having more than one meaning or semantic interpretation. Hirst further identifies three types of lexical ambiguity namely, homonymy, polysemy and categorial ambiguity. Homonymy refers to a situation where a word has two or more unrelated meanings e.g. 'bank' which can mean "a piece of land along a river" or "a place for keeping money and valuables". Polysemy refers to a situation where a word has two or more meanings that are related e.g. "broad" can mean "wide", "large", "full" or "complete". Categorial ambiguity refers to where a word has two or more meanings, which are also of different grammatical categories e.g. 'sink' can mean "a domestic basin for washing in the kitchen or toilet" which is a noun, or "to descend gradually to a lower level" which is a verb. Copi (1978) calls this type ambiguity equivocation.

\section{Syntactic Ambiguity}

Trask (1993) refers to this as structural ambiguity which occurs because of the complex structural construction of a given utterance or expression. Hirst (1982) describes it as a situation where a given sentence or expression is capable of 
having more than one semantic interpretation or realization, usually due to the fact that such a grammatical construction can be given or assigned alternative grammatical constituents. $\mathrm{He}$ also identifies three types of syntactic ambiguity, namely, attachment ambiguity, gap finding ambiguity and analytical ambiguity.

Attachment ambiguity occurs when a modifier may be logically or meaningfully attached to more than one grammatical item e.g. "He killed the guard with a sword" which can mean "The guard was killed with a sword" or "The guard having a sword was killed by him". Gap finding ambiguity occurs when there is more than a place or position that a grammatical item can occupy or fill in an expression. The example given by Hirst (1982) is "These are the girls that the boys debated about fighting" which can mean "The boys debated with the girls on the topic of fighting" or "The boys debated among themselves about fighting the girls". Analytical ambiguity, to Hirst, occurs when there is possibility of a complex analysis of the constituents of a grammatical construction. He gave the example "the students objected (to) the teacher that they could not hear" which can mean "They don't want a teacher that they won't hear when he/she speaks" or "They complained/protested because they could not hear the teacher".

\section{Phonological Ambiguity}

Copi (1978) describes phonological ambiguity as fallacy of accent which is a kind of semantic multiplicity resulting from the way words or expressions are accented or articulated, hence, can be regarded as speech or phonetic ambiguity. Hirst (1982) identifies two main types namely, homophones and homographs. Homophones refer to words which have similar or the same pronunciation but which have different spellings and meanings. For example, words like 
'for', 'fore' and 'four' all have similar pronunciation hence, can be confusing in some contexts. Other examples are 'hare' and 'hair' pronounced as /he $\partial(r) /$ meaning "a fast running field animal like a rabbit with long ears" and "the thread-like growth on the human head or skin" respectively. Also 'bear' and 'bear' are pronounced as /be $(r) /$ meaning "to carry, have, tolerate or endure" and "to reveal or uncover" respectively.

Homographs, however, are words which though do not have the same pronunciation or meaning, but which have exactly the same spelling hence, can also create semantic confusion. For example, the word 'bow' can be realized as (bju/ meaning "a piece of wood bent into a curve with a tight string for shooting arrows" and as /bau/ meaning "bending of the head or body as in greeting or sign of respect". The word 'row' can also be realized as /rdu/ meaning "a number of people on a line" or as /rau/ meaning "an uproar or quarrel". The word "bow" will be semantically confusing in an expression like "The warrior/warlord was given a bow as a sign of victory".

\section{Semantic Ambiguity}

This is identified by de Swart (1998) and Yusuf (1984) as a form of ambiguity just like the lexical, syntactic and phonological forms of ambiguity. According to Yusuf, semantic ambiguity occurs when an expression with a single structural analysis still has double or multiple semantic interpretations. Hence, to him, the expression "I saw John in the class" which can mean "I saw John when I was in the class", "I saw John when he was in the class and I was outside" and "I saw John when we were both in the class" is 
an example of semantic ambiguity. This is because it can only be structurally analysed as "I [S] saw [P] John [O] in the class [A]". To him, this is unlike Kemson's (1977) expression "We saw her duck" which can mean "We saw the duck that belongs to her" or "We saw her trying to avoid being seen". This is because the expression has two corresponding structural analyses "We [S] saw [P] her duck [O]" and "We [S] saw [P] her [O] duck [C]" respectively. The ' $S$ ' in the bracket represents 'subject', ' $P$ ' stands for 'predicator' ' $O$ ' for 'object', ' $\mathrm{A}$ ' for 'adverbial' and ' $\mathrm{C}$ ' for 'complement'.

Multiple postmodification of nominal groups often lead to ambiguity which the contexts may not disambiguate, hence this study of nominal group postmodification in the continuous writing of the selected students.

\section{Data Analysis and Discussion}

The ambiguous expressions to be analysed here are those resulting from complex nominal group post-modification discovered in the continuous writing of some Higher National Diploma Students of The Federal Polytechnic, Ede, Osun State, Nigeria who offered English courses as compulsory minors. Eighty (80) scripts of the said students were randomly selected from four (4) main departments of the institution namely, Department of Business Administration, Department of Statistics, Department of Building Technology and Department of Science Laboratory Technology. Twenty (20) scripts were selected from the category of the students in each of the said departments and the continuous writing that is, letters, essays or reports of the students were linguistically examined with a view to detecting semantic multiplicity. As a result of the linguistic examination of the said continuous writing, nineteen (19) ambiguous expressions resulting from complex multiple post-modification were identified. Below are the various ambiguous expressions and the possible syntactic 
combinations that can result in their double or multiple semantic interpretations:

[1] the phone booth in front of the building that is painted red

[1a] the building in front of which the phone booth is located is painted red

booth in front of the building that is painted red

noùn head + prepositional phrase + relative clause

[ booth ] +[ in front of the building +that is painted red ]

[1b] the phone booth located in front of the building is painted red

booth in front of the building that is painted red

noun head + prepositional phrase + relative clause

[ bơth + in front of the building] + [ that is painted red ]

[2] a night guard with a big police dog that was watching passers-by

[2a] the big police dog with the guard was watching passers-by

guard with a big police dog that was watching passers-by noutn head + prepositional phrase + relative clause [guard] $+[$ with a big police dog + that was watching passers- by ] 
Ambiguity and Nominal Group Multiple Post Modification...

[2b] the night guard with a big police dog that was watching passers-by

guard with a big police dog that was watching passersby noun head+ prepositional phrase + relative clause [guard +with a big police dog]+[that was watching passers-by

[3] the pregnant woman with a baby that was waving to us

[3a] the baby with the pregnant woman was waving to us

$\frac{\text { woman }}{\downarrow} \quad$ with a baby $\quad$ that was waving to us noun head + prepositional phrase + relative clause [woman ] +[ with a baby + that was waving to us ]

[3b] the pregnant woman with the baby was waving to us

woman with a baby that was waving to us

noun head + prepositional phrase + relative clause

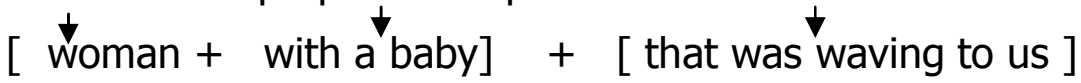

[4] Special marshal in front of the vehicle that I showed you

[4a] the special marshal is/was in front of the vehicle that I showed you

$\frac{\text { marshal }}{\downarrow} \quad$ in front of the vehicle that I showed you noun head + prepositional phrase + relative clause [ marshal ] + [ in front of the vehicle + that I showed you ] 
[4b] the special marshal that I showed to you is/was in front of the vehicle

marshal in front of the vehicle that I showed you noun head + prepositional phrase + relative clause [ marshal + in front of the vehicle ] $+[$ that I showed you ]

[5] the picture of the lecturer that was shown to me [5a] the lecturer that was shown to me is in the picture

picture of the lecturer that was shown to me noun head + prepositional phrase + relative clause [picture] + [ of the lecturer + that was shown to me ] [5b] the picture that was shown to me was that of the lecturer

picture of the lecturer $\quad$ that was shown to me noun head + prepositional phrase + relative clause [Picture + of the lecturer] + [that was shown to me] [6] the student on the chair whose legs are bad [6a] the legs of the chair, on which the student is, are bad

$\frac{\text { student }}{\downarrow} \quad$ on the chair $\quad$ whose legs are bad noun head + prepositional phrase + relative clause [ student ] + [ on the chair + whose legs are bad ] 
Ambiguity and Nominal Group Multiple Post Modification...

\section{[6b] the legs of the student who is on the chair are bad student on the chair whose legs are bad noùn head + prepósitional phrase + relative clause [ student + on the chair] + [ whose legs are bad ]}

One thing that is peculiar to the above analysed ambiguous expressions [1] to [6] is the fact that they all have similar syntactic or structural pattern which is evident in their constituent combinations. We have the noun head of the various complex phrases directly followed by prepositional phrases which are also followed by relative clauses that is, the "noun head + prepositional phrase + relative clause" structural combination. It should be noted that the square brackets are used to show the intended combination of the grammatical constituents of the complex noun phrases that can result in the possible semantic realization or interpretations. For example, for the first interpretation of ambiguous expression [1], the noun head "booth" in the first bracket is modified by both the prepositional phrase "in front of the building" and the relative clause "that is painted red" which occupy the second bracket. For the second interpretation of the ambiguous expression [1], the noun head 'booth' and (noun head of the) prepositional phrase which both appear in the first bracket are modified by the following post modifying relative clause "that is painted in red" meaning that it is the phone booth that is painted in red. The same thing goes for the other five ambiguous expressions because they also have relative clauses that can either modify the nouns in preceding post modifying prepositional phrases or the noun heads of the main complex noun phrases. Other ambiguous expressions are analysed below: 
[7] the two nurses in front of the clinic facing the female hostel

[7a] the clinic in front of which the two nurses are, is facing the female hostel

nurses in front of the clinic facing the female hostel noun head + prepositional phrase + non-finite clause [nułses] + [in front of the clinic +facing the female hostel]

[7b] the two nurses in front of the clinic, are facing the female hostel

nurses in front of the clinic facing the female hostel noun head + prepositional phrase + non-finite clause [nurses + in front of the clinic ] + [facing the female hostel]

[8] students in the vehicle making horrible noise

[8a] the vehicle in which the students are, is making horrible noise

$\underline{\text { students in the vehicle making horrible noise }}$ noùn head+ prepositional phrase + non-finite clause [students ] + [ in the vehicle + making horrible noise ] 
Ambiguity and Nominal Group Multiple Post Modification...

\section{[8b] the students who are in the vehicle are making horrible noise}

$\frac{\text { students }}{\downarrow} \quad$ in the vehicle making horrible noise noun head + prepositional phrase + non-finite clause [students + in the vehicle ] + [making horrible noise]

\section{[9] policemen with guns pointing at us}

[9a] the guns with the policemen are pointing at us

$\frac{\text { policemen with guns }}{\downarrow} \quad \frac{\text { pointing at us }}{\downarrow}$

noun head + prepositional phrase + non-finite clause

[policemen] + [with guns $+\quad$ pointing at us]

[9b] the policemen who are with the guns are pointing at us

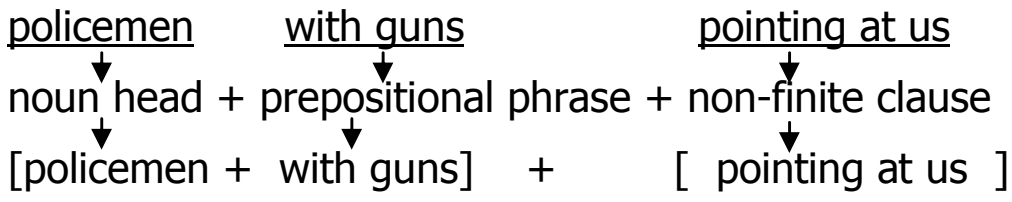

The above analysed ambiguous expression [7] to [9] also have similar grammatical constituent combination or structural pattern because the heads of the complex noun phrases or nominal groups are post-modified by prepositional phrases and non-finite clauses in the same sequence. For example, "nurses", the head of ambiguous expression [7] is post-modified by the prepositional phrase "in front of the clinic" and the non-finite clause "facing the female hostel". The ambiguity is as a result of the non-finite clause coming after the prepositional phrase where the non-finite clause can 
modify "clinic" the noun (head) in the preceding prepositional phrase or "nurses" the head of the main complex nominal group. The same thing goes for ambiguous expression [8] and [9] which also have heads of complex noun phrases followed by post modifying prepositional phrases and nonfinite clauses in the same order as ambiguous expression [7].

[10] security man holding a dog with a chain on the neck

[10a] the chain is on the neck of the dog the security man is holding

man holding a dog with a chain on the neck noun head + non-finite clause + prepositional phrase [man] + [ holding a dog + with a chain on the neck ] [10b] the chain is on the neck of the man who is holding the dog

man holding a dog with a chain on the neck noừn head + non-finite clause + prepositional phrase [man + holding a dog $]+[$ with a chain on the neck]

[11] the man bringing a boy with a scar on his face [11a] the boy the man is bringing has a scar on his face man bringing a boy with a scar on his face noun head + non-finite clause + prepositional phrase [man ] + [ bringing a boy + with a scar on his face ] 
Ambiguity and Nominal Group Multiple Post Modification...

\section{[11b] the man bringing the boy has a scar on his face}

$\frac{\text { man }}{\downarrow} \quad$ bringing a boy $\quad$ with a scar on his face

noun head + non-finite clause + prepositional phrase

$[$ man + bringing a boy $]+$ [with a scar on his face]

Ambiguous expressions [10] and [11] above have postmodifying elements whose structural combination or syntactic pattern is a reversal of those of ambiguous expressions [7] to [9]. This is because while the noun head of [10] and [11] are directly followed by non-finite clauses that are followed by prepositional phrases, the noun heads of [7] to [9] are directly followed by post modifying prepositional phrases that are followed by non-finite clauses. But the ambiguity of [10] and [11] still arises from the fact that the second post-modifying prepositional phrases can modify both the nouns in the preceding non-finite clauses and the heads of the whole complex noun phrases.

\section{[12] portrait of a bouquet of flower on the table}

\section{[12a] the portrait is that of a bouquet of flower placed on the table}

portrait of a bouquet of flower on the table noùn head + prepositiohal phrase ${ }^{1}+$ prepositional phrase $^{2}$ [portrait] + [of a bouquet of flower + on the table] [12b] the portrait of a bouquet of flower is on the table

portrait of a bouquet of flower on the table noùn head + prepositional phrase $^{1}+$ prepositional phrase $^{2}$ [portrait + of a bouquet of flower $]+[$ on the table] 


\section{[13] a girl in a new sports car with a very smooth body}

[13a] the new sports car in which the girl is has a very smooth body

girl in a new sports car with a very smooth body noun head + prepositional phrase ${ }^{1}+$ prepositional phrase $^{2}$ [girl] + [in a new sports car + with a very smooth body]

[13b] the girl in the new sports car has a very smooth body

girl in a new sports car $\quad$ with a very smooth body noun head + prepositional phrase ${ }^{1}+$ prepositional phrase $^{2}$ $[$ girl + in a new sports car ] + [with a very smooth body] Ambiguous expressions [12] and [13] show that it is possible to have post-modifiers of the same kind in a complex nominal group. "In a new sports car" and "with a very smooth body" in [13] as well as "of bouquet of flower" and "on the table" in [12] are prepositional phrases. This is the reason why the first is tagged or described as "prepositional phrase ${ }^{1 "}$ while the second is described as prepositional phrase ${ }^{2 \prime \prime}$.

[14] the fact that no man is an Island which is known to everybody

[14a] the fact is that no man is an Island known to everybody

fact that no man is an Island $\frac{\text { which is known to }}{\downarrow}$ $\underset{\downarrow}{\text { noun head }}+\underset{\downarrow}{\operatorname{appositive}} \underset{141}{\downarrow}+\underset{\downarrow}{\text { relative clause }}$ 
Ambiguity and Nominal Group Multiple Post Modification...

[fact] + [that no man is an Island + which is known to everybody]

\section{[14b] that no man is an Island is a fact that is known to everybody}

$\frac{\text { fact }}{\downarrow}$ that no man is an Island $\frac{\text { which is known to }}{\downarrow}$ everybody

noun head + appositive clause $+\quad$ relative clause $[$ fact + that no man is an Island] + [which is known to everybody ]

The above ambiguous expression [14] slightly differs from those already analysed in that its first post-modifying element is an appositive clause followed by a relative clause which has appeared in some of the already discussed and analysed expressions. The remaining ambiguous expressions, as will be seen, also differ in that they are grammatically complete expressions with verbal elements. The postmodifying elements are complex because they can possibly be attached to the heads of the object noun phrases or the verbal elements in the expressions thereby resulting in double or multiple semantic interpretations.

[15] cult members shot the old man in the porter's lodge

\section{[15a] the old man who usually stayed at the porter's lodge was shot}

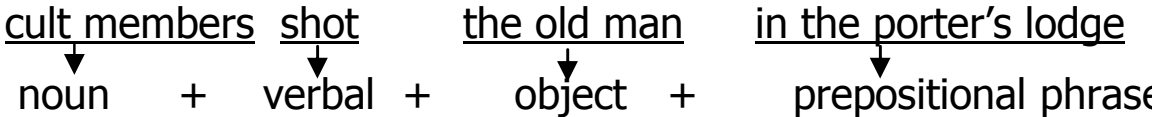
noun phrase phrase

[cult members] + [shot] + [the old man + in the porter's lodge] 
[15b] it was in the porter's lodge that cult members shot the old man

cult members shot the old man in the porter's lodge noun + verbal + object + prepositional phrase element phrase phrase

[cult members] $+[$ shot $+\stackrel{t}{t}$ old man $]+\stackrel{t}{[}$ in the porter's lodge]

\section{[16] I told my closest friend in our hostel}

[16a] It was my closest friend in our hostel that I told

I told my closest friend in the porter's lodge

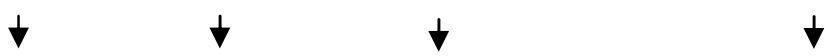

noun + verbal + object + prepositional phrase element noun phrase phrase

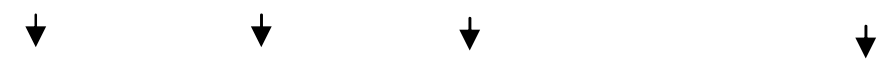

$[$ I ] + [ told ] + [ the closest friend + in the porter's lodge]

\section{[16b] it was in our hostel that I told my closest friend}

$\frac{\text { I }}{\downarrow} \frac{\text { told }}{\downarrow} \frac{\text { my closest friend }}{\downarrow} \frac{\text { in the porter's lodge }}{\downarrow}$ noun + verbal + object + prepositional phrase element noun phrasẹ phrase

[ I ] + [ told + the closest friend $]+$ [in the porter's lodge] 
Ambiguity and Nominal Group Multiple Post Modification...

[17] the class representative called the boy in the class [17a] it was the boy who was in the class when the rep. called him

class representative called the boy in the class subject noun + verbal + object + prepositional head noun phrase [class Rep. + phrase element [called ] + [the boy + in the class]

[17b] it was the representative who was in the class when he called the boy

class rep. called the boy in the class

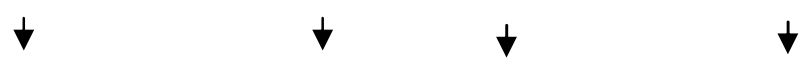

subject noun + verbal + object+ prepositional head element noun phrase phrase

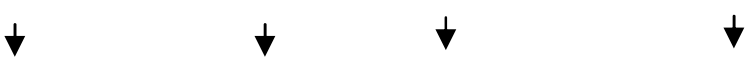

[class rep. $]+$ [ called + the boy $]+[$ in the class $]$

[17c] the representative and the boy were both in the class when he called him

class rep. called the boy in the class

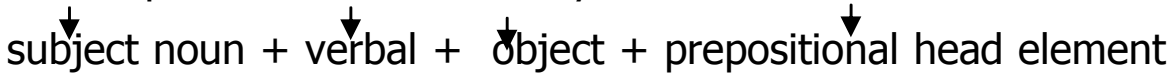
noun phrase phrase

[class rep.] + [called + the boy $]+$ [in the class]

[18] We saw our lecturer looking through the window of his office 
[18a] our lecturer was looking through the window of his office when we saw him

$\frac{\text { we saw }}{t} \frac{\text { our lecturer looking through the window of his office }}{t}$ $\mathrm{S}(\mathrm{N})+(\mathrm{V})+$ object + prepositional head element

$\mathrm{NP} \quad \mathrm{VP} \downarrow \downarrow$

[we]+saw ] +[our lecturer +looking through the window of

his office ]

[18b] we saw our lecturer by looking through the window of his office

$\frac{\text { we }}{\downarrow} \frac{\text { saw }}{\downarrow} \frac{\text { our lecturer }}{\downarrow} \frac{\text { looking through the window of his }}{\downarrow}$ office

$\mathrm{S}(\mathrm{N})+\mathrm{V}+$ object + prepositional head element

$\mathrm{NP}+\mathrm{VP} \quad \downarrow$

[we $]+[$ saw + our lecturer $]+$ looking through the window of

his office ]

[19] most students live in double bedded rooms in Agbale hall

[19a] most students (not all) live in double bedded rooms in Agbale hall

most students $\frac{\text { live in double bedded rooms }}{\downarrow}$ in Agbale hall noun + verbal + prepositional + prepositional phrase element phrase ${ }^{1} \quad$ phrase $^{2}$ [most students $]+[$ live $]+[$ in double bedded rooms + in

Agbale hall] 
Ambiguity and Nominal Group Multiple Post Modification...

\section{[19b] most of the students who live in Agbale hall live in double bedded rooms]}

most students live in double bedded rooms in Agbale hall nठun + verbal + prepositional + prepositional

phrase element phrase $^{1} \quad$ phrase $^{2}$

[most students] + [live + in double bedded rooms $]+[$ in Agbale

hall ]

It is apparent from the analysis done so far that multiple post modification as a means of ensuring clarity of ideas or brevity needs to be used with caution because it can also make ideas or expressions so modified to be susceptible to double or multiple semantic interpretations. When this happens, such ambiguous ideas or expressions, unknown to the communicator, disseminate both the intended and the unintended meanings or messages.

The analysis of the ambiguities resulting from complex post modification shows that those with the "noun head + prepositional phrase + relative clause" structural combination are the commonest type because they are six out of the nineteen ambiguous expressions analysed i.e. [1] to [6] which is about $32 \%$ of the total. Those with the "noun head + prepositional phrase + non-finite clause" structural combination are three out of the nineteen i.e. [7] to [9] which represent about $16 \%$ of the total. Those with "noun head + non-finite clause + prepositional phrase" structural combination are two i.e. [10] and [11] which constitute $11 \%$ of the total. Those with "noun head + prepositional phrase ${ }^{1}+$ prepositional phrase" are just two i.e. [12] and [13] which also represent $11 \%$ of the total. Those with the constituent combination "subject noun phrase + verbal element + object 
noun phrase + prepositional phrase" are also three i.e. [15] to [17] which represent $16 \%$ of the total. Those with the noun "noun head + appositive clause + relative clause"; "noun phrase + verbal element + prepositional phrase $^{1}+$ prepositional phrase ${ }^{2 \prime \prime}$ and "subject noun phrase + verbal element + object noun phrase + non-finite clause" constitute $5 \%$ each because we have just one example each of such structural combination namely, [14], [19] and [18] respectively.

One thing that is also glaring from the syntactic-semantic analysis of the discovered ambiguous expressions is the fact that multiple post-modification of the ambiguous complex nominal groups results more frequently in dual or double semantic interpretations than multiple semantic interpretations. For example, out of the whole nineteen ambiguous expressions discovered and analysed only expression [17] has triple semantic interpretations and this represents just $5.3 \%$ of the total ambiguous expressions. Others which represent $94.7 \%$ of the total ambiguous expressions have just two semantic interpretations each. The only logical linguistic panacea to the problem of double or multiple semantic interpretations resulting from complex multiple post modification of nominal groups is proper disambiguation. However, this can be viewed from two perspectives, the reader's need disambiguation perspective and the writers' need disambiguation perspective. Hirst (1982) defines disambiguation from the reader's need disambiguation perspective as "the process of determining the correct and appropriate sense of lexically or structurally ambiguous grammatical constituents". It is in the light of this that Moulton and Robinson (1981) also states that 
Ambiguity and Nominal Group Multiple Post Modification...

disambiguation relies on the context dependent pragmatic information given linguistically or non-linguistically. However, disambiguation from the writer's need disambiguation perspective can refer to the use of appropriate linguistic devices or techniques to remove ambiguities of expressions when revising, proof reading or editing continuous writing or write-ups. This is to ensure that expressions used communicate exactly the writer's intended meanings/messages.

One good method or technique for the resolution or disambiguation of ambiguity of complex multiple post modification is the selection of appropriate specific-purpose lexemes. In ambiguous expression [4] "the Special Marshal in front of the vehicle that I showed you" for example, the relative pronoun 'who' usually used for persons only can be used to replace 'that' a neutral or general purpose relative pronoun to have "the special marshal in front of the vehicle who I showed you" if the second meaning of the ambiguous expression [4] is the intended. But if the first meaning of the ambiguous expression [4] is the intended, the 'that' can be replaced with "which" a relative pronoun used for non-human or inanimate things to have "the special marshal in front of the vehicle which I showed you". Other expressions like [2] and [5] can be so resolved or disambiguated using specificpurpose relative pronouns. In ambiguous expression [10] "security man holding a dog with a chain on the neck" the definite article 'the' can be replaced with the possessive pronoun 'its' to have the first semantic interpretation of the expression that is, "security man holding a dog with a chain on its neck". The possessive pronoun 'his' can also be used to replace "the" to have "security man holding a dog with a chain on his neck" which is the second meaning of the expression. 
Another good disambiguation method or technique that can help to resolve ambiguities of complex multiple post modification is syntactic rearrangement. This method or technique enables post modifying items or elements to be placed close to the items they modify in such a way that the intended meanings of such properly modified expressions will be unequivocal. For example, the ambiguous expression [13] "a girl in a new sports car with a very smooth body" can be syntactically re-organized/rearranged as either "a new sports car with a very smooth body, in which a girl is" or as "a girl with a very smooth body in a new sports car" to have its first and second meanings, respectively. In the same vein, ambiguous expression [11] "the man bringing a boy with a scar on his face" can be resolved via syntactic re-organisation to have either "the baby with a scar on his face brought by the man" or "the man with a scar on his face bringing the boy" instead of the ambiguous "the man bringing the boy with a scar on his face".

\section{Conclusion}

This is a descriptive study of nominal group multiple postmodification in the continuous writing of some Nigerian Polytechnic students. This paper has been able to show that multiple postmodification in the English nominal group can constitute problems for learners and users of English. It is, therefore, suggested that it would be better for teachers of English, especially in a second language situation, to first emphasize clarity in the presentation of learners' language output rather than brevity. In addition, it is obvious that learners would only be able to use multiple postmodification in the nominal group successfully after they have acquired the 
Ambiguity and Nominal Group Multiple Post Modification...

art of careful ordering of lexical items in English for different communicative purposes.

\section{References}

Bloor, T and Bloor, M. 2004. The Functional Analysis of English. $2^{\text {nd }}$ ed. London: Edward Arnold.

Cayne, B. S. and Lechner, D. E. (ed) 1992. The New Lexicon Webster's Encyclopedic Dictionary of the English language. Danbury C. T. Lexicon Publication Inc.

Copi, I. M. 1978. Introduction to Logic. New York: Macmillan Publishing Company.

de Swart, H. 1998. Introduction to Natural Language Semantics. Stanford: CSLI Publishers.

Halliday, M.A. K. 1994. Functional Grammar. 2nd ed. London: Edward Arnold.

Hirst, G. 1982. Semantic Interpretation and the Resolution of Ambiguity. London: Oxford University Press.

Hornby, A. S. (6th ed.) 2000. Oxford Advanced Learner's Dictionary of Current English. London: Oxford University Press.

Kemson, R. 1977. Semantic Theory. New York: Harper and Row.

Kent, N. 1990. The student writer's guide to writing and language. Leckhampton Stanley Thornes (Publishers) Ltd.

Moulton, J. and Robinson, G. 1981. The Organisation of Language. London: Longman Group Limited.

Oluga, S. O. 2003. Ambiguity and the language of advertisement via the mass media and related means: 
The need for proper disambiguation. In Multidisciplinary Journal of Research Development. 2. (2), 117-123.

Quirk, R. Greenbaum, S., Leech, G. and Svartik, J. 1972. $A$ Grammar of Contemporary English.. Essex: Longman Group Limited.

Quirk R., Greenbaum, S., Leech, G., and Svartvik, J. 1985. $A$ Comprehensive Grammar of the English Language, New York: Longman Group Limited.

Ruwet, N. 1983. An Introduction to Generative English. Amsterdam: North Holland Pub. Co.

Trask, R. L. 1993. A Dictionary of Grammatical Terms in Linguistics. London: Routledge Blackwell.

Yusuf, Y. K. 1984. Semantic ambiguity: The case of English usage in Nigerian politics". Unpublished M. A. Thesis, University of Ife (now OAU), Nigeria.

1990. Tragicality of the moral condemnation of deliberate ambiguity and vagueness in political language. Odu: A Journal of West African Studies. 37, $72-81$. 